Marcos Desidério RICCI

Maria Carolina Formigon ${ }^{1}$

LUCIA Maria Martins ZULIANI ${ }^{1}$

Denis Seitti Aoki ${ }^{1}$

Bruna Salani Mota'

JOSÉ Roberto FILASSI ${ }^{1}$

José Roberto Morales Piato'

EDmund Chada Baracat ${ }^{2}$

Original Article

Keywords

Body mass index

Chemotherapy, adjuvant

Breast neoplasms/drug therapy

Obesity

Overweight

Palavras-chave

Índice de massa corpórea

Quimioterapia adjuvante Neoplasias da mama/quimioterapia

Obesidade

Sobrepeso

\title{
Variations in the body mass index in Brazilian women undergoing adjuvant chemotherapy for breast cancer
}

\author{
Variações no indice de massa corpórea em mulheres brasileiras \\ submetidas à quimioterapia adjuvante por câncer de mama
}

Abstract

PURPOSE: To evaluate variations in the body mass index in patients undergoing adjuvant chemotherapy for breast cancer, and to associate these changes with patient's age and adjuvant chemotherapy regimen. METHODS: We performed a retrospective cohort study in order to correlate any variation in the body mass index before and after adjuvant chemotherapy with patient's age and adjuvant chemotherapy regimen. Patients who received any form of prior hormone therapy, such as tamoxifen or aromatase inhibitors, were excluded. We selected data for 196 patients with stage I to III breast cancer who were treated by radical or conservative surgery and received adjuvant chemotherapy at the Cancer Institute of the State of São Paulo, Brazil. RESULTS: Before adjuvant chemotherapy, $67.8 \%$ of patients were classified as overweight or obese according to their body mass indices. Around $66.3 \%$ (95\% Cl 59.7-73.0) of the patients exhibited an increase in the body mass index after adjuvant chemotherapy. The average age of all patients was $56.3 \pm 11.3$ years. Participants whose body mass index increased were younger than those with no increase $(54.7 \pm 11.1$ versus $59.3 \pm 11.2$ years; $p=0.007)$. Patients were treated with the following adjuvant chemotherapy regimens: doxorubicin, cyclophosphamide, and paclitaxel (AC-T, 129 patients, 65.8\%); 5-fluoracil, doxorubicin, and cyclophosphamide (36 patients, 18.4\%); cyclophosphamide, methotrexate, and 5-fluoracil (16 patients, 8.2\%); docetaxel and cyclophosphamide (7 patients, 3.6\%); and other regimen (8 patients, 4. 1\%). The AC-T regimen showed a statistically significant association with increase in the body mass index ( $p<0.001$ by ANOVA). CONCLUSIONS: Most patients with breast cancer showed an increase in the body mass index after adjuvant chemotherapy, especially after the AC-T chemotherapy regimen.

\section{Resumo}

OBJETIVO: Avaliar variações no índice de massa corpórea em pacientes que estão passando por quimioterapia devido ao câncer de mama, e relacionar tais alterações com a idade da paciente e o regime de quimioterapia. MÉTODOS: Estudo de coorte retrospectivo que correlacionou variações no índice de massa corpórea pré- e pós-quimioterapia com a idade da paciente e o regime de quimioterapia. Foram excluídas as pacientes que receberam terapia hormonal prévia, seja como tamoxifeno ou inibidores da aromatase. Os dados de 196 pacientes com estágio I a III de câncer de mama foram selecionados, e elas foram tratadas por cirurgia radical ou conservadora que receberam quimioterapia adjuvante no Instituto do Câncer do Estado de São Paulo, Brasil. RESULTADOS: Antes da quimioterapia adjuvante, 67,8\% das pacientes foram classificadas com sobrepeso ou obesas de acordo com seus índices de massa corpórea. Aproximadamente 66,3\% (IC95\% 59,7-73,0) das pacientes exibiram aumento no índice de massa corpórea após a quimioterapia adjuvante. A média

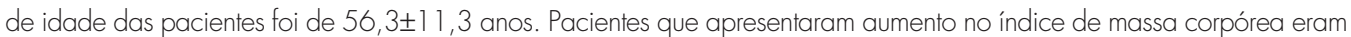
mais jovens do que aquelas que não apresentaram aumento algum $(54,7 \pm 11,1$ versus $59,3 \pm 11,2$ anos; $\mathrm{p}=0,007)$. As pacientes foram tratadas com os seguintes regimes de quimioterapia: doxorrubicina, ciclofosfamida e paclitaxel (AC-T, 129 pacientes, 65,8\%); 5-fluoracil, doxorrubicina e ciclofosfamida (36 pacientes, 18,4\%); ciclofosfamida, metotrexato e 5-fluoracil (16 pacientes, 8,2\%); docetaxel e ciclofosfamida (7 pacientes, 3,6\%) e outros regimes (8 pacientes, 4, $1 \%$ ). regime AC-T mostrou uma relação significativa com o aumento do índice de massa corpórea ( $<<0,001$ por ANOVA). CONCLUSÕES: A maioria das pacientes com câncer de mama mostrou um aumento no índice de massa corpórea pósquimioterapia adjuvante, especialmente após o regime de quimioterapia AC-T.

Correspondence

Marcos Desidério Ricci Avenida Doutor Enéas de Carvalho Aguiar, 255 - Floor $10^{\circ}$ Zip code: $05403-000$ São Paulo (SP), Brazil

Received 07/07/2014

Accepted with modifications $09 / 25 / 2014$
Instituto do Câncer do Estado de São Paulo, Departamento de Obstetrícia e Ginecologia, Faculdade de Medicina, Universidade de São Paulo - USP - São Paulo (SP), Brazil.

IInstituto do Câncer do Estado de São Paulo, Departamento de Obstetrícia e Ginecologia, Faculdade de Medicina, Universidade de São Paulo - USP - São Paulo (SP), Brazil.

2Departamento de Obstetrícia e Ginecologia, Faculdade de Medicina, Universidade de São Paulo - USP - São Paulo (SP), Brazil. 
Introduction

In Brazil, breast cancer is the most common malignant neoplasm for women and one of the ten main causes of death ${ }^{1}$. Steroid hormones heavily influence on the disease. Increased estrone and estradiol and reduced sex hormone-binding globulin levels, which result in an increased bio-disposable fraction of estrogen, have been observed in patients with high body mass index $(\mathrm{BMI})^{2}$. As a reference measurement used internationally by the World Health Organization (WHO), BMI is determined by dividing a person's weight by their height squared ${ }^{3}$.

Chemotherapy (CTx) may be adjuvant or neoadjuvant, depending on whether the cytotoxic agents are administered after or before surgical treatment, respectively. CTx plays an important role in reducing recurrence and improves global survival. However, CTx agents act not only on cancer cells, but also on normal ones, causing some side effects such as nausea, vomiting, loss of appetite, alopecia, mucositis, weakness, fatigue, phlebitis, and myelotoxicity ${ }^{4-6}$. Most of these effects have an influence on body weight. Although some women report weight loss, weight gain is more common after $\mathrm{CTx}^{7-9}$.

Causes of weight gain after CTx have not been fully established, and its etiology seems to be multifactorial. Weight gain occurs because of a positive energy balance and some studies report an increase in the ingestion of calories due to hyperphagia ${ }^{5}$. Others describe reductions in the energy expended, basal metabolic rate, and physical activity ${ }^{9,10}$. Another important factor is the combination of glucocorticoids and antiemetics used to minimize the side effects of CTx agents ${ }^{8,11}$. Psychological stress-related emotional volatility and start of menopause may also be related to weight gain during $\mathrm{CTx}^{12}$. Interruption of ovarian function reduces metabolism, muscle mass, and energy expended, and also stimulates fat accumulation ${ }^{13-15}$.

In addition to being a risk factor, obesity is related to poorer global survival and specific survival for breast cancer patients ${ }^{16-18}$. Obesity is associated with locally advanced disease at diagnosis and, consequently, a poorer prognosis ${ }^{11,16,19}$. The mechanism has not been well-established, but high BMI values have been usually associated with greater concentrations of circulating sex hormones, insulin, and insulin growth factor, leading to a disequilibrium in the relationship between cell differentiation and apoptosis with a consequent progression and proliferation of tumor cells ${ }^{16-18,20}$.

The purposes of this study were to evaluate variations in the BMI of breast cancer patients undergoing adjuvant CTx, and to relate these changes with the age and CTx regimen employed.
Methods

The goal of this retrospective cohort study was to correlate any variation between pre- and post-CTx BMI with patient's age and CTx regimen. Out of 221 patients with non-metastatic breast cancer, 196 treated with adjuvant chemotherapy were included in this study. Data were extracted from the electronic records of 196 patients with stage I to III breast cancer who were treated in 2011 at the Cancer Institute of the State of São Paulo (ICESP), in Brazil. The research protocols and the consent process were approved by the Ethics Committee (48/2010). Patients were treated with radical or conservative surgeries and received adjuvant CTx, according to interval protocols. Participants who received any form of prior hormone therapy, such as tamoxifen or aromatase inhibitors, were excluded.

The weight and height of all patients were measured during the first nursing outpatient consultation before the beginning of CTx, using a digital scale (Filizola, Anthropometic Electronic PL 200; $200 \mathrm{~kg} \times 50 \mathrm{~g}$ ). Weight was reevaluated within 30 days after CTx. BMI was calculated as weight (in $\mathrm{kg}$ ) divided by height (in $\mathrm{m}^{2}$ ). Patients were classified according to their BMIs, following the guidelines of the National Institutes of Health and the National Heart, Lung, and Blood Institute, as follows: $17 \geq \mathrm{BMI}<18.5$, slightly underweight; $18.5 \geq \mathrm{BMI}<25$, normal body weight; $25 \geq \mathrm{BMI}<30$.0, overweight; $30.0 \geq \mathrm{BMI} \leq 34.9$, grade $\mathrm{I}$ obese; $35 \geq \mathrm{BMI} \leq 39.9$, grade II obese; and $\mathrm{BMI}>40$, grade III obese ${ }^{3}$.

The Kolmogorov-Smirnov test was used to test for the normality of the distribution of continuous variables. Student's $t$-test or, when convenient, the Mann-Whitney's test, was used to compare measurements from two independent groups. The analysis of variance (ANOVA) was used to compare three or more independent groups. Pre- and post-CTx BMI distributions were compared with Student's $t$-test for paired measurements. For comparison of these distributions by the type of treatment performed, ANOVA was used. When necessary, sub-hypotheses were tested with Fisher's Least Significant Difference (LSD) method.

Results

Before starting CTx, 67.8\% ( $\mathrm{n}=133)$ of patients had a $\mathrm{BMI} \geq 25$. Among them, $40.3 \%$ were classified as overweight, $16.8 \%$ as grade I obese, $8.7 \%$ as grade II obese, and $2.0 \%$ as grade III obese. After CTx, $66.3 \%$ of the patients (95\% CI 59.7-73.0) had an increase in their BMI. The average (mean \pm standard deviation) age of all patients was $56.3 \pm 11.3$ years old. Patients with an increase in their BMI after CTx were younger than those without it $(54.7 \pm 11.1$ versus $59.3 \pm 11.1$ years old, $\mathrm{p}=0.007)$, as seen in Table 1 . 
There was no difference between the pre-CTx BMIs in the groups of patients with or without a post-CTx increase in the BMI $\left(27.3 \pm 5.1\right.$ versus $28.3 \pm 5.7 \mathrm{~kg} / \mathrm{m}^{2}$, $\mathrm{p}=0.2$ ). Among all patients, the average pre- and post-CTx BMIs were $27.7 \pm 5.3$ and $28.4 \pm 5.3 \mathrm{~kg} / \mathrm{m}^{2}$, respectively, with an average variation of $0.7 \pm 2.1 \mathrm{~kg} / \mathrm{m}^{2}(\mathrm{p}<0.001)$. This variation was increased or decreased in the group of patients whose BMI increased or not, respectively, after CTx (for both $\mathrm{p}<0.001$; Table 1).

The following CTx regimens were employed: doxorubicin, cyclophosphamide, and paclitaxel
(AC-T, 129 patients, 65.8\%); 5-fluoracil, doxorubicin, and cyclophosphamide (FAC, 36 patients, 18.4\%); cyclophosphamide, methotrexate, 5-fluoracil (CMF, 16 patients, $8.2 \%$ ); docetaxel and cyclophosphamide (CT, 7 patients, 3.6\%); and other regimens (8 patients, $4.1 \%)$, including cycles of paclitaxel and trastuzumab, paclitaxel alone, or docetaxel and cyclophosphamide (AC) (Table 2). Patients who received AC-T were younger (54.2 \pm 11 years) than those undergoing other regimens. The AC-T regimen showed an association with the post-CTx BMI change ( $p<0.001$ by ANOVA), as seen in Table 3 .

Table 1. Descriptive statistics for age, body mass index, and variation in the body mass index before and after chemotherapy for patient groups, with and without an increase in the body mass index post-chemotherapy

\begin{tabular}{|c|c|c|c|c|c|c|c|}
\hline Variable & Increase in BMI & n & Mean & SD & Min. & Median & Max. \\
\hline \multirow{3}{*}{$\begin{array}{l}\text { Age } \\
\text { (years) }\end{array}$} & No & 66 & 59.3 & 11.1 & 36.0 & 59.0 & 84.0 \\
\hline & Yes & 130 & 54.7 & 11.0 & 27.0 & 54.0 & 82.0 \\
\hline & Total & 196 & 56.3 & 11.3 & 27.0 & 55.0 & 84.0 \\
\hline \multirow{3}{*}{$\begin{array}{l}\text { Pre-CTx BMI } \\
\left(\mathrm{kg} / \mathrm{m}^{2}\right)\end{array}$} & No & 66 & 28.3 & 5.7 & 19.3 & 27.2 & 48.7 \\
\hline & Yes & 130 & 27.3 & 5.1 & 17.5 & 26.7 & 40.1 \\
\hline & Total & 196 & 27.7 & 5.3 & 17.5 & 27.0 & 48.7 \\
\hline \multirow{2}{*}{$\begin{array}{l}\text { Post-CTx BMI } \\
\left(\mathrm{kg} / \mathrm{m}^{2}\right)\end{array}$} & Yes & 130 & 29.2 & 5.2 & 17.9 & 28.6 & 43.3 \\
\hline & Total & 196 & 28.4 & 5.3 & 17.9 & 27.7 & 46.0 \\
\hline \multirow{2}{*}{$\begin{array}{l}\text { Variation in BMI } \\
\left(\mathrm{kg} / \mathrm{m}^{2}\right)\end{array}$} & No & 66 & -1.5 & 1.3 & -5.7 & -1.3 & 0.0 \\
\hline & Yes & 130 & 1.8 & 1.4 & 0.1 & 1.5 & 6.6 \\
\hline
\end{tabular}

BMI: body mass index; SD: standard deviation; CTx: chemotherapy; Min: minimum; Max.: maximum.

Table 2. Descriptive statistics for age, pre- and post-chemotherapy body mass index based on the chemotherapy regimen

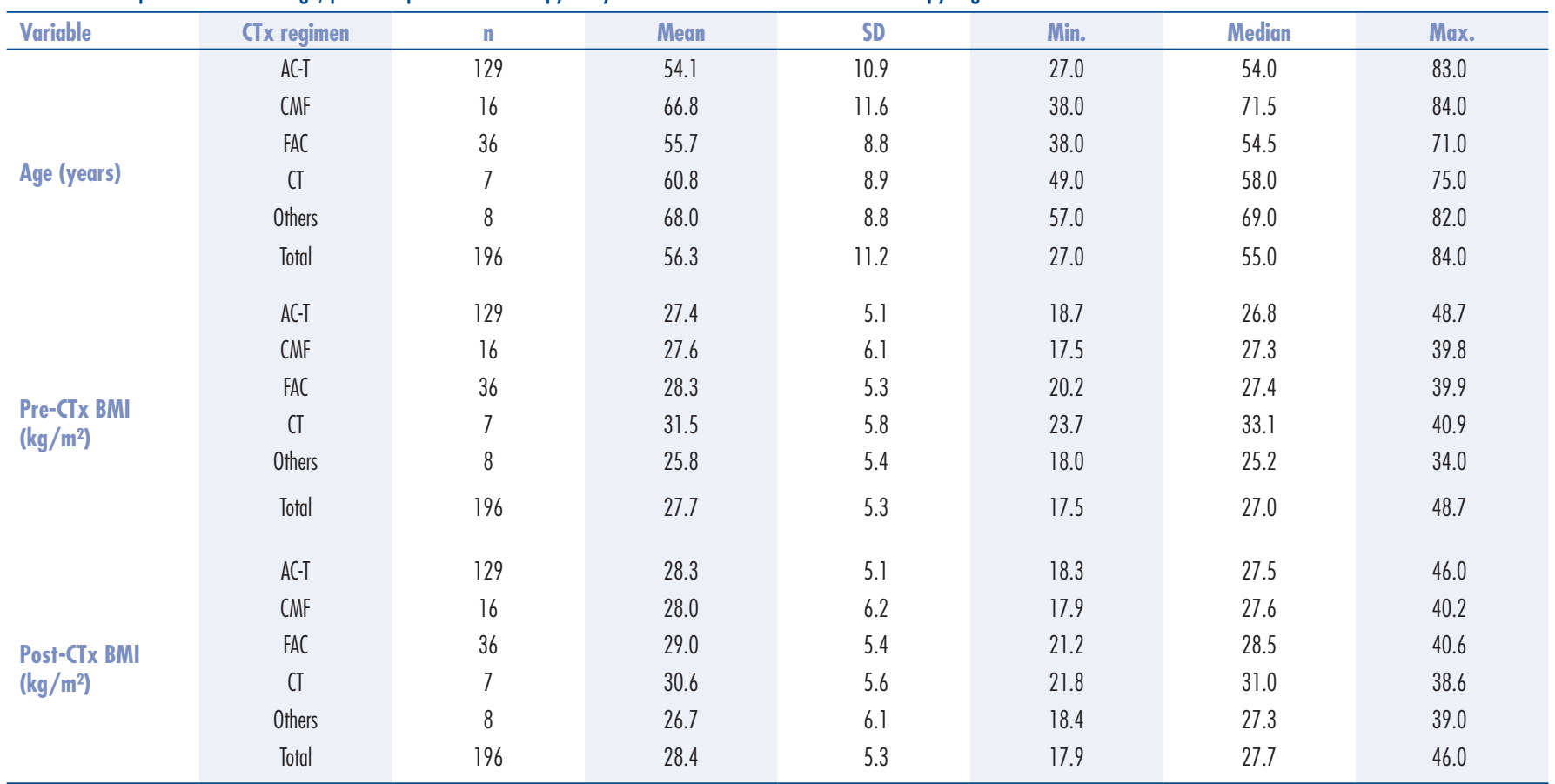

CTx: chemotherapy; SD: standard deviation; Min: minimum; Max: maximum; BMI: body mass index; AC-T: doxorubicin, cyclophosphamide, and paclitaxel;

CMF: cyclophosphamide, methotrexate, 5-fluoracil; FAC: 5-fluoracil, doxorubicin, and cyclophosphamide; CT: docetaxel and cyclophosphamide. 
Table 3. Descriptive statistics for pre- and post-chemotherapy body mass indices and comparison between them for each chemotherapy regimen

\begin{tabular}{lcccc}
\hline CTx regimen & Evaluation & Mean & SD & p-value \\
\hline \multirow{2}{*}{ AC-T } & Pre-CTx BMI & 27.4 & 5.1 & \\
& Post-CTx BMI & 28.3 & 5.1 & $<0.001$ \\
\multirow{4}{*}{ CMF } & Pre-CTx BMI & 27.6 & 6.1 & \\
& Post-CTx BMI & 28.0 & 6.2 & 0.4 \\
\multirow{2}{*}{ FAC } & Pre-CTx BMI & 28.3 & 5.3 & \\
& Post-CTx BMI & 29.0 & 5.4 & 0.06 \\
\multirow{4}{*}{ CT } & Pre-CTx BMI & 31.5 & 5.8 & \\
& Post-CTx BMI & 30.6 & 5.6 & 0.2 \\
\multirow{2}{*}{ Others } & Pre-CTx BMI & 25.8 & 5.4 & \\
& Post-CTx BMI & 26.7 & 6.1 & 0.2 \\
\hline
\end{tabular}

CTx: chemotherapy; SD: standard deviation; AC-T: doxorubicin, cyclophosphamide, and paclitaxel; CMF: cyclophosphamide, methotrexate, 5-fluoracil; FAC: 5-fluoracil, doxorubicin, and cyclophosphamide; CT: docetaxel and cyclophosphamide: BMI: body mass index.

\section{Discussion}

Among patients who started adjuvant CTx, 67.8\% were overweight. This percentage is slightly higher than the $31 \%$ overweight reported in a study including 9,527 patients diagnosed with breast cancer from 1997 to 2007 at participating centers of the National Comprehensive Cancer Network $^{21}$. A Korean study found differences in the BMI between East Asian and Western women ${ }^{22}$. In that study, of the East Asian patients evaluated before $\mathrm{CTx}, 72.8 \%$ were of normal weight, $22.8 \%$ were overweight, and $4.3 \%$ were obese. Similar data about East Asian women were found in a study including Taiwanese breast cancer patients, which recorded an average pre-CTx BMI of $23.8 \mathrm{~kg} / \mathrm{m}^{2}{ }^{23}$.

Although most patients experienced an increase in their BMI, they remained in the overweight band with BMI values between 25.0 and $29.9 \mathrm{~kg} / \mathrm{m}^{2}$. Even though many studies have recorded increases in weight and BMI after breast cancer treatment, a systematic review, which included variations in body composition based on the use of imaging exams that quantified adipose tissue and lean body mass, such as densitometry, tomography, and magnetic resonance, did not record a consistent increase in the body weight ${ }^{6}$. Even when there was no weight gain, these patients often had changes to their bodies, with an increase in body fat and reductions in muscle mass and bone density ${ }^{6,24}$. Two other reviews showed that 50 to $96 \%$ of the patients with initial-stage breast cancer gained significant weight during adjuvant treatment, ranging from 2.5 to $6.2 \mathrm{~kg}^{25}$. However, weight gains of $10 \mathrm{~kg}$ or more were not uncommon ${ }^{26}$.

A criticism of studies that only consider variations in weight is that they do not record the evolution in the body mass composition of skeletal, bone, and adipose tissues during cancer treatment. Body mass does not fully reflect the potentially important changes in lean or adipose tissues. Nonetheless, it is recommended that breast cancer survivors keep their body weights within normal limits during and after treatment ${ }^{14,15,27-29}$.

Considering that CTx-induced ovarian failure occurs in 50 to $70 \%$ of women in pre-menopause who receive adjuvant $\mathrm{CTx}$, the post-CTx weight, fat, and lean masses changes essentially mirror those observed in healthy women who undergo natural menopause ${ }^{30}$. In our study, the group of patients who had an increase in their BMIs after CTx was younger than the group with the opposite characteristics. Theoretically, patients with cancer diagnosis who have already experienced changes in their body mass during menopause will have fewer variations throughout cancer treatment. Future studies may want to stratify the women's menopausal state to analyze changes in the BMI. Population studies in women have demonstrated that specific changes, including an increase in body fat and reduction in lean mass, coincide with aging and are significantly accentuated from the start of natural menopause, with higher rates of increased weight in the initial post-menopausal years ${ }^{30,31}$.

Anthracycline-based CTx regimens were associated with the greatest rise in BMI, with a statistically significant value for the AC-T regimen and a near-significant one for the $\mathrm{FAC}$ regimen. The $\mathrm{CMF}$ and $\mathrm{CT}$ regimens were not statistically related to an increase in the BMI. Changes in BMI during anthracycline-based CTx have been associated with poorer prognosis, in terms of increased recurrence and mortality rates ${ }^{13,14}$. However, other studies have recorded only slight weight gains or unchanged weight with anthracycline-based regimens ${ }^{22,24,32}$.

One limitation of our study is the small number of patients who received the CMF regimen. Other investigations with more participants have shown that such regimen, or those based on cyclophosphamide, were related to higher rates of weight gain ${ }^{22,33,34}$. One mechanism responsible for this increased weight gain is the higher dose of cyclophosphamide, which is an alkalizing agent that induces amenorrhea and menopause more often than anthracycline ${ }^{35}$.

In addition to adjuvant therapy, be it CTx, hormone therapy, or immunotherapy with trastuzumab-type monoclonal antibodies, metabolic and endocrine factors related to an increase in weight gain after cancer diagnosis are strongly associated with higher risk of recurrence and reduction in survival rates ${ }^{14,29,36-38}$.

Advances in the clinical management of breast cancer, including early detection, new CTx regimens, and targeted treatments with anti-estrogens or trastuzumab, 
have improved survival rates for women with breast cancer. However, weight gain and unfavorable changes in body composition, particularly central adiposity, after treatment, can increase morbidity and mortality due to other chronic degenerative diseases, such as diabetes, cardiovascular disease, and colon cancer. There is a need for campaigns targeted towards this group of women, and for institutional programs focused on helping patients maintain their BMIs within normal standards during and after CTx.

Most patients with breast cancer showed an increase in BMI after adjuvant CTx. This change was mostly associated with the AC-T CTx regimen. In future studies to identify the start of chemotherapy, menopausal state may relate to the role of adjuvant therapy on weight gain, or hormonal changes in menopause.

\section{References}

1. Brasil. Ministério da Saúde. Instituto Nacional de Câncer José Alencar Gomes da Silva. Estimativa 2012: incidência de câncer no Brasil. Rio de Janeiro: INCA; 2011.

2. Demark-Wahnefried W, Platz EA, Ligibel JA, Blair CK, Courneya KS, Meyerhardt JA, et al. The role of obesity in cancer survival and recurrence. Cancer Epidemiol Biomarkers Prev. 2012;21 (8):1244-59.

3. National Heart, Lung, and Blood Institute. Clinical guidelines on the identification, evaluation, and treatment of overweight and obesity in adults. Bethesda: NHLBI; 1998.

4. Protani M, Coory M, Martin JH. Effect of obesity on survival of women with breast cancer: systematic review and meta-analysis. Breast Cancer Res Treat. 2010;123(3):627-35.

5. Niraula S, Ocana A, Ennis M, Goodwin PJ. Body size and breast cancer prognosis in relation to hormone receptor and menopausal status: a meta-analysis. Breast Cancer Res Treat. 2012;134(2):769-81.

6. Sheean PM, Hoskins K, Stolley M. Body composition changes in females treated for breast cancer: a review of the evidence. Breast Cancer Res Treat. 2012;135(3):663-80.

7. Heideman WH, Russell NS, Gundy C, Rookus MA, Voskuil DW. The frequency, magnitude and timing of post- diagnosis body weight gain in Dutch breast cancer survivors. Eur J Cancer. 2008;45(1): $119-26$.

8. Lankester KJ, Phillips JE, Lawton PA. Weight gain during adjuvant and neoadjuvant chemotherapy for breast cancer: an audit of 100 women receiving FEC or CMF chemotherapy. Clin Oncol (R Coll Radiol). 2002;14(1):64-7.

9. Litton JK, Gonzalez-Angulo AM, Warneke CL, Buzdar AU, Kau SW, Bondy $M$, et al. Relationship between obesity and pathologic response to neoadjuvant chemotherapy among women with operable breast cancer. J Clin Oncol. 2008;26(25):4072-7.

10. Trédan $O$, Bajard A, Meunier A, Roux P, Fiorletta I, Gargi $T$, et al. Body weight change in women receiving adjuvant chemotherapy for breast cancer: a French prospective study. Clin Nutr. 2010;29(2):87-191.

11. Azrad M, Demark-Wahnefried W. The association between adiposity and breast cancer recurrence and survival: A review of the recent literature. Curr Nutr Rep. 2014;3(1):9-15.

12. Obi N, Gornyk D, Heinz J, Vrieling A, Seibold P, Chang-Claude J, et al. Determinants of newly diagnosed comorbidities among breast cancer survivors. J Cancer Surviv. 2014;8(3):384-93.

13. Thivat $E$, Thérondel S, Lapirot $O$, Abrial $C$, Gimbergues $P$, Gadéa $E$, et al. Weight change during chemotherapy changes the prognosis in non metastatic breast cancer for the worse. BMC Cancer. 2010;10:648.
14. de Azambuja E, McCaskill-Stevens W, Francis P, Quinaux E, Crown JP, Vicente $M$, et al. The effect of body mass index on overall and disease-free survival in node-positive breast cancer patients treated with docetaxel and doxorubicin-containing adjuvant chemotherapy: the experience of the BIG 02-98 trial. Breast Cancer Res Treat. 2010;1 19(1):145-53.

15. Walshe JM, Denduluri N, Swain SM. Amenorrhea in premenopausal women after adjuvant chemotherapy for breast cancer. J Clin Oncol. 2006;24(36):5769-79.

16. Eichholzer M, Huang DJ, Modlasiak A, Schmid SM, Schötzau A, Rohrmann S, et al. Impact of body mass index on prognostically relevant breast cancer tumor characteristics. Breast Care (Basel). 2013;8(3):192-8.

17. Mazzarella L, Disalvatore D, Bagnardi V, Rotmensz N, Galbiati D, Caputo S, et al. Obesity increases the incidence of distant metastases in oestrogen receptor-negative human epidermal growth factor receptor 2-positive breast cancer patients. Eur J Cancer. 2013;49(17):3588-97.

18. Chen S, Chen CM, Zhou Y, Zhou R, Yu KD, Shao ZM. Obesity and overweight is associated with worse pathological response to neoadjuvant chemoterapy among Chinese women with breast cancer. PLoS One. 2012;7(7):e41380.

19. Kaviani A, Neishaboury M, Mohammadzadeh N, AnsariDamavandi $M$, Jamei K. Effects of obesity on presentation of breast cancer, lymph node metastasis and patient survival: a retrospective review. Asian Pac J Cancer Prev. 2013; 14(4):2225-9.

20. Del Fabbro E, Parsons $\mathrm{H}$, Warneke CL, Pulivarthi K, Litton JK, Dev $R$, et al. The relationship between body composition and response to neoadjuvant chemotherapy in women with operable breast cancer. Oncologist. 2012;17(10):1240-5.

21. Brewster AM, Etzel C, Zhou R, Wong Y, Edge S, Blayney DW, et al. The impact of obesity on receipt of adjuvant chemotherapy for breast cancer in the National Comprehensive Cancer Network (NCCN) centers. Breast Cancer Res Treat. 201 1;130(3):897-904.

22. Lee KH, Keam B, Im SA, Kim TY, Han SW, Oh DY, et al. Body mass index is not associated with treatment outcomes of breast cancer patients receiving neoadjuvant chemotherapy: Korean data. J Breast Cancer. 2012;15(4):427-33.

23. Liu LN, Wen FH, Miaskowski C, Lin YC, Wang JS, Jeng C, et al. Weight change trajectory in women with breast cancer receiving chemotherapy and the effect of different regimens. J Clin Nurs. 2014;23(19-20):2757-68.

24. Freedman R, Aziz N, Albanes D, Hartman T, Danforth D, Hill S, et al. Weight and body composition changes during and after adjuvant chemotherapy in women with breast cancer. J Clin Endocrinol Metab. 2004;89(5):2248-53. 
25. Demark-Wahnefried W, Winer EP, Rimer BK. Why women gain weight with adjuvant chemotherapy for breast cancer. J Clin Oncol. 1993; 11 (7): 1418-29.

26. Demark-Wahnefried W, Rimer BK, Winer EP. Weight gain in women diagnosed with breast cancer. J Am Diet Assoc. 1997;97(5):519-29.

27. Barnett GC, Shah M, Redman K, Easton DF, Ponder BA, Pharoah PD. Risk factors for the incidence of breast cancer: do they affect survival from the disease? J Clin Oncol. 2008;26(20):3310-6.

28. Dawood S, Broglio K, Gonzalez-Angulo AM, Kau SW, Islam R, Hortobagyi GN, et al. Prognostic value of body mass index in locally advanced breast cancer. Clin Cancer Res. $2008 ; 14(6): 1718-25$.

29. Majed B, Moreau T, Asselain B; Curie Institute Breast Cancer Group. Overweight, obesity and breast cancer prognosis: optimal body size indicator cut-points. Breast Cancer Res Treat. 2009; 1 15(1): 193-203.

30. Wang Q, Hassager C, Ravn P, Wang S, Christiansen C. Total and regional body-composition changes in early postmenopausal women: age-related or menopause-related? Am J Clin Nutr. 1994;60(6):843-8.

31. Ronco AL, De Stefani E, Deneo-Pellegrini H, Quarneti A. Diabetes, overweight and risk of postmenopausal breast cancer: a case-control study in Uruguay. Asian Pac J Cancer Prev. 2012;13(1):139-46.
32. Campbell KL, Lane K, Martin AD, Gelmon KA, McKenzie DC. Resting energy expenditure and body mass changes in women during adjuvant chemotherapy for breast cancer. Cancer Nurs. 2007;30(2):95-100.

33. Rock CL, Flatt SW, Newman V, Caan BJ, Haan MN, Stefanick $\mathrm{ML}$, et al. Factors associated with weight gain in women after diagnosis of breast cancer. Women's Healthy Eating and Living Study Group. J Am Diet Assoc. 1999;99(10):1212-21.

34. Ingram C, Brown JK. Patterns of weight and body composition change in premenopausal women with early stage breast cancer: has weight gain been overestimated? Cancer Nurs. 2004;27(6):483-90.

35. Minton SE, Munster PN. Chemotherapy-induced amenorrhea and fertility in women undergoing adjuvant treatment for breast cancer. Cancer Control. 2002;9(6):466-72.

36. Camoriano JK, Loprinzi CL, Ingle JN, Therneau TM, Krook JE, Veeder $\mathrm{MH}$. Weight change in women treated with adjuvant therapy or observed following mastectomy for node-positive breast cancer. J Clin Oncol. 1990;8(8):1327-34.

37. Chlebowski RT, Weiner JM, Reynolds R, Luce J, Bulcavage L, Bateman JR. Long-term survival following relapse after 5-FU but not CMF adjuvant breast cancer therapy. Breast Cancer Res Treat. 1986;7(1):23-30.

38. Vance V, Mourtzakis M, McCargar L, Hanning R. Weight gain in breast cancer survivors: prevalence, pattern and health consequences. Obes Rev. $2011 ; 12(4): 282-94$. 